\title{
Over-tree sprinkling reduces abnormal shapes in 'Bing' sweet cherries
}

\author{
Stephen M. Southwick $\square$ Kenneth A. Shackel $\square \quad$ James T. Yeager \\ Wesley K. Asai a Matt Katacich, Jr.
}

\begin{abstract}
The 'Bing' sweet cherry produces increased numbers of abnormal fruit shapes when grown in certain regions in California, rendering the fruit less marketable. Postharvest under- and over-tree sprinkler irrigation led to a reduction in the production of abnormal fruit shapes indicating that canopy climate modification may be an alternative to growers producing 'Bing' cherries in those regions where these abnormal fruit shapes are prevalent.
\end{abstract}

'Bing' sweet cherry is the leading cherry cultivar in California and the Western U.S. It was selected in Oregon from the seed of the Republican' cultivar in 1875. The cultivar rose to prominence because of its size, taste, firmness and degree of shipability. Commercial sweet cherry (Prunus avium) production in California, (which includes 'Bing' and other cultivars) has been localized in regions where climate is moderated by ocean or elevation, and where prolonged periods of high temperature (greater than $95^{\circ} \mathrm{F}$ ) are less common than on valley floors. Grower experience has shown that higher quality cherries are produced in sites with more moderate temperatures.

The California sweet cherry industry is localized on approximately 8,000 acres in San Joaquin County. Additional acreage is located in Stanislaus, Contra Costa, San Benito, Santa Clara, EI Dorado, and Sacramento Counties, among others. Historically the market for sweet cherries has been relatively strong and the recent advent of a fresh sweet cherry market in Japan has helped to strengthen demand.

'Bing' is identified as a superior cultivar in cherry marketing. In general, the earlier the fruit matures in the season the higher the price received. Consequently, growers are looking for ways to mature 'Bing' cherries as early in the season as possible. Fruit maturity can be advanced by warmer temperatures, especially higher night temperatures. The fact that early maturing sweet cherries attract strong prices, coupled with the fact that many San Joaquin County trees are diseased and dying, has led to increased planting of sweet cherries in warmer, nontraditional sites of Stanislaus, Merced, Fresno, Tulare, Kings and Kern Counties. Stanislaus County has especially seen many of the new commercial 'Bing' plantings. These sites have warmer spring temperatures with earlier flowering and fruit maturation. Postharvest summer temperatures, however, are also high, and evidence suggests that the production of abnormal fruit from a given orchard may be partly due to high canopy temperatures during the previous year.

Crinkle leaf, deep suture and variegation are recognized genetic disorders of both 'Bing' and 'Black Tartarian'. The crinkle leaf disorder occurs in nursery stock and bearing trees and is perpetuated through propagation. Affected nursery trees are usually rogued out before sale. Crinkle leaf and deep suture disorders can be found on mature bearing trees in spite of the fact that they were symptomless when planted. Branches on trees affected by crinkle leaf are less productive and the fruit may have abnormal shapes. Deep suture is bud-perpetuated like crinkle leaf, but limbs showing leaf symptoms of deep suture also have fruit with an indented or depressed ventral suture (see photos on $\mathrm{p}$. 25). In some of the worst cases, the fruit may have indented suture lines extending to the stone. These fruit are referred to as "sutured". There is a minimum tolerance set by the state inspection service for the length of the suture ( $3 / 8$ inch), beyond which the fruit becomes much less valuable and cannot be shipped as a U.S \#1.

As more 'Bing' cherries have come into bearing age, especially in regions south of Lodi in the San Joaquin Valley, the production of sutured fruit has become more pronounced. However, leaf symptoms normally associated with fruit suturing are not always found. Other abnormal fruit shapes (e.g. fruit "doubles" or aborted secondary fruit "spurs" shown on p. 25) are also seen in Bing" cherry when they are grown south of Lodi. The production of abnormal fruit from a given orchard may be a consequence of high canopy temperatures affecting flower bud development during the previous year. Canopy temperature can be modified directly by over-tree sprinkler irrigation, but can also be modified indirectly by irrigation practices which influence evaporative cooling from the leaves.

Our goal in these and other studies has been to quantify the problem of abnormal fruit production in 'Bing' sweet cherry in and among various growing districts, and to identify important environmental factors contributing to this problem. This study sought to determine whether cultural practices which were designed to influence canopy temperatures, such as over-tree sprinkling or irrigation method, could economically reduce abnormal fruit production.

\section{Treatments, experimental design}

In 1988, we selected a 200-acre orchard located on the west side of Patterson where many abnormal and sutured 'Bing' cherry fruit had been observed. Patterson itself is located on the eastern slope of the coast range. We identified southern and northern locations within that orchard based on the grower's observation of a consistent difference in the percentage of abnormal fruit found from the two locations over the years. Trees in both locations growing on Prunus mahaleb rootstocks were arranged into randomized complete block designs consisting of nine trees per plot. Two irrigation treatments, drip and mini-sprinkler, consisting of four replicates each and separated by at least three guard trees in both directions $(20 \mathrm{x}$ 20 foot spacing) were established in the southern location. Drip-irrigated trees were supplied with water from five emitters which delivered one gal/hr. Minisprinkler irrigated trees were supplied with water by Dan emitters (Netafim Irrigation, Inc.) which delivered $11 \mathrm{gal} / \mathrm{hr}$. Emitters were placed at every space between trees in a row. Consequently, the pattern and amount of water delivered to trees of each irrigation treatment varied.

Seasonal irrigation began approximately April 1 and finished September 1 with each tree receiving approximately 48 hr of water per week. A mini-sprinkler and a mini-sprinkler plus over-tree irriga tion treatment were established in the northern location, each replicated six times. Over-tree sprinkling was applied to individual trees beginning the first week of July by a single $11 \mathrm{gal} / \mathrm{hr}$ mini-sprinkler which was supported by an 8-meter tall steel pipe connected to the under-tree irrigation system. The combined over-tree sprinkler and under-tree irrigation system was turned on during irrigation, and on 
positions (south and north tree bottoms) (table 3). The production of sutured fruit were not always associated with canopy position. However, there was an interaction between orchard location and canopy position indicating that more sutured fruit were found in lower canopy positions of the northern location at Patterson.

\section{Discussion}

The deep suture disorder of 'Bing' cherry is believed to be accompanied by characteristic leaf symptoms. However, we have observed that fruits with deep suture could be found on 'Bing' trees with symptomless leaves. We also found regional differences in the levels of sutured,

spurred and doubled fruit produced. Hollister, situated in the southern end of the Santa Clara Valley is influenced by the Pacific Ocean, and most fruit produced in Hollister were normal. Stockton and Lodi which are located in California's primary cherry producing region, are influenced by delta breezes, which help to moderate temperature extremes.

The western edge of Patterson along the coast range is a non-traditional cherry growing region and is blocked from the moderating influence of the ocean or delta. The highest percentage of abnormal fruit were produced in the Patterson location. Of the abnormal fruit produced, deep suture was the most prevalent at all loca-

\begin{tabular}{|c|c|c|c|c|c|}
\hline \multirow[b]{2}{*}{ Orchard location } & \multirow[b]{2}{*}{ Irrigation treatment } & \multicolumn{4}{|c|}{ Fruit classification } \\
\hline & & Normal & Sutured & Spurred & Doubled \\
\hline \multirow{2}{*}{$\begin{array}{l}\text { Patterson } \\
\text { (southern location) }\end{array}$} & Drip & $50.8 e^{*}$ & $49.2 a$ & $O c$ & $\mathrm{Ob}$ \\
\hline & Mini-sprinkled & $49.4 \mathrm{e}$ & $49.6 \mathrm{a}$ & $1.0 \mathrm{abc}$ & $\mathrm{Ob}$ \\
\hline \multirow{3}{*}{$\begin{array}{l}\text { Patterson } \\
\text { (northern location) }\end{array}$} & Over-tree sprinkled & $79.3 d$ & $20.0 \mathrm{~b}$ & $0.6 \mathrm{bc}$ & $0.1 \mathrm{~b}$ \\
\hline & Mini-sprinkled & $70.8 d$ & $28.3 b$ & $0.5 b c$ & $0.4 a b$ \\
\hline & $\begin{array}{l}\text { Mini-sprinkled plus } \\
\text { over-tree sprinkled }\end{array}$ & $77.1 d$ & $22.5 b$ & $0.3 \mathrm{bc}$ & $0.1 \mathrm{~b}$ \\
\hline Hollister & & $99.8 \mathrm{a}$ & $0.2 e$ & $O C$ & $\mathrm{Ob}$ \\
\hline Stockton & & $86.0 \mathrm{c}$ & $10.0 \mathrm{c}$ & $3.1 \mathrm{a}$ & $0.9 a$ \\
\hline Lodi & & $93.7 \mathrm{~b}$ & $4.8 \mathrm{~d}$ & $1.0 \mathrm{abc}$ & $0.5 \mathrm{ab}$ \\
\hline
\end{tabular}

"Mean separation within columns by Duncan's multiple range test, $5 \%$ level of significance.

TABLE 3. Effect of orchard location and canopy position between mini-sprinkler irrigated trees on the production of normal, sutured, spurred and doubled fruit at Patterson, California in 1989

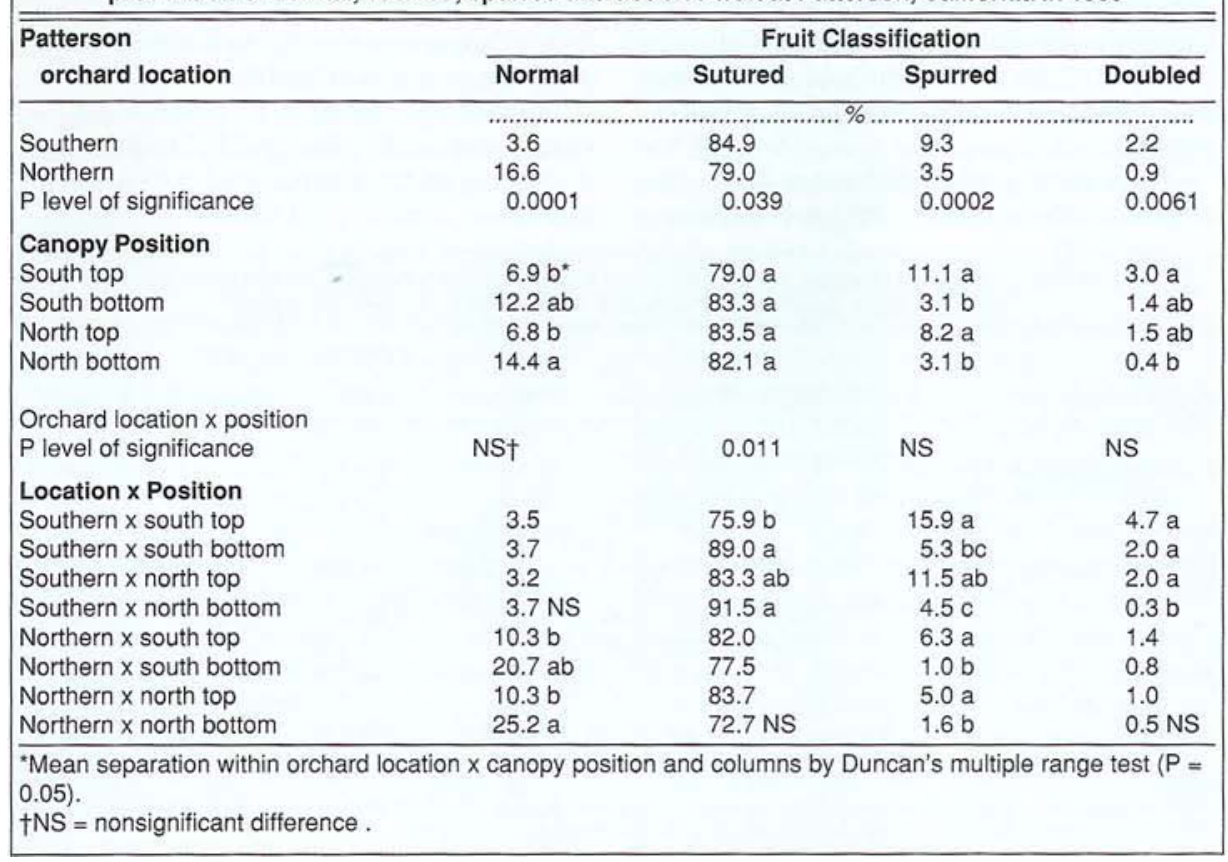

tions. Fruit with deep suture was substantially reduced by over-tree sprinkling. Trees were over-tree sprinkled through the hottest months of the growing season (July to September) during which flowers were differentiating for the following season. Temperatures commonly exceeded $104^{\circ} \mathrm{F}$ at the Patterson location between 5 and 6 p.m. and the night temperatures were also warm.

In additional work, we have found that canopy temperatures are reduced and tree-water relations are altered as a function of over-tree sprinkling. However, the over-tree sprinkling also led to leaf drop. Sodium, chlorine, boron and other ions in well water are believed to have contributed to the leaf drop. 'Bing' cherries typically matured in mid-to late-May, one month before the over-tree sprinkling treatment began. As a result, leaf drop may not have affected the following season's yield and its components. This hypothesis is currently under study. We suspect that lower temperatures and/or altered water relations in over-tree sprinkled trees helped to reduce the production of sutured fruit and to increase the production of normal fruit at the Patterson orchard location. Future work will attempt to differentiate effects of temperature from altered tree-water status with regard to the production of sutured 'Bing' cherry fruit. In addition, we are assessing the periods during the growing season in which overtree sprinkling may reduce the production of sutured fruit with a minimum of leaf drop.

\section{Conclusions}

These studies suggest that regions with climates moderated by coastal breezes tend to have fewer 'Bing' cherries affected by deep suture, spurs and doubles than regions without coastal influences. Deep suture was the most prevalent fruit abnormality and was reduced in the orchard location where the problem was most severe by over-tree sprinkler irrigation in conjunction with normal under-tree minisprinkler irrigation. Where summer temperatures are not excessive, or where their effects on canopy temperature and treewater relations can be mitigated by overtree sprinkling, normal flower and fruit production in 'Bing' cherries can be promoted.

S. M. Southwick is Extension Pomologist, $K$. A. Shackel is Assistant Professor and Pomologist, and J. T. Yeager is Staff Research Associate, Department of Pomology, UC Davis. W. $K$. Asai is Farm Advisor, Stanislaus County and $M$. Katacich, Jr. is an orchard manager with MEM Farm Management.

The authors acknowledge Sun World, Inc., for partial funding of this work. 